RU Высшая народная школа как пространство самоактуализации человека третьего возраста

Гордина О. В., Гордин А. И.

\begin{abstract}
Аннотация. Цель исследования - определить психолого-педагогические условия, способствующие самоактуализации человека третьего возраста в образовательном пространстве Высшей народной школы. В статье авторы описали основные подходы к определению понятий «самоактуализация», «третий возраст», уточнили сущность понятия «Высшая народная школа», обосновали социальнопсихологические, педагогические и социальные эффекты андрагогического взаимодействия субъектов, действующих в её образовательном пространстве. Научная новизна заключается в разработке организационно-методической системы образования людей третьего возраста, способствующей их самоактуализации с учетом современных тенденций образования взрослых. В результате проведенного эмпирического исследования подтверждена значимость образования в третьем возрасте для самоактуализации личности, выявлены психолого-педагогические условия организации данной деятельности и обоснована её оптимальная форма - Высшая народная школа.
\end{abstract}

\title{
Higher Public School as Space for Third-Age Person's Self-Actualization
}

\author{
Gordina O. V., Gordin A. I.
}

Abstract. The paper aims to identify psychological and pedagogical conditions promoting a third-age person's self-actualization in Higher Public School educational space. The authors describe the basic approaches to defining the concepts "self-actualization", "third age", clarify the essence of the notion "Higher Public School", reveal socio-psychological, pedagogical and social effects of andragogic interaction between subjects of educational space. Scientific originality of the study includes developing an organizational and methodological basis of third-age education focused on self-actualization, taking into account modern trends in adult education. The research findings are as follows: relying on empirical research results, the authors justify importance of third-age education for a personality's self-actualization, reveal psychological and pedagogical conditions of educational process organization and substantiate its optimal model Higher Public School.

\section{Введение}

Проблема самоактуализации человека третьего возраста в современной России требует глубокого осмысления. Устойчивой тенденцией является увеличение доли пожилых людей в структуре населения страны, что обусловлено снижением суммарного коэффициента рождаемости и увеличением продолжительности жизни. В среднем в регионах России пенсионеры составляют около $30 \%$ от общего числа жителей. Необходимо учитывать этот фактор при осуществлении государственной социальной политики, создавая условия для активного долголетия данной категории граждан. Формирование культуры позитивного старения является актуальной задачей для современного общества, решение которой требует серьезного междисциплинарного научного исследования и глубокого изучения специалистами в сфере образования, культуры, здравоохранения, социальной защиты населения.

Актуальность исследования обусловлена наличием противоречий: между потребностью общества в обеспечении активного долголетия и самоактуализации человека третьего возраста и недостаточной разработанностью психолого-педагогического инструментария для сопровождения этих процессов; между успешной апробацией опыта образования представителей старшего поколения в Высшей народной школе и недостаточным осмыслением и презентацией данного опыта для широкой педагогической общественности. Мы полагаем, что сфера образования взрослых могла бы стать пространством апробации жизненных сил и самоактуализации людей третьего возраста, но приходится констатировать недостаточную разработанность правового, 
методологического, методического и технологического обеспечения неформального и информального образования пожилых людей в современной России.

Задачи данного исследования:

- выявление специфики процесса самоактуализации личности в третьем возрасте;

- анализ теоретико-методологических основ организации образования людей третьего возраста в образовательном пространстве Высшей народной школы;

- определение педагогических, социально-психологических, социальных эффектов андрагогического взаимодействия в Высшей народной школе;

- обоснование педагогических условий, способствующих самоактуализации людей третьего возраста.

Для решения поставленных задач нами использовались следующие методы исследования: теоретические (анализ философской, психолого-педагогической и социологической литературы), эмпирические (социальнопедагогический эксперимент по созданию и устойчивому функционированию Высшей народной школы на базе вуза).

Теоретической базой исследования послужили публикации российских авторов: Е. Е. Вахромова [1], С. Г. Вершловского [2], В. Г. Доброхлеб [7], М. А. Казаковой [8], Д. А. Леонтьева [9], Н. П. Литвиновой [10], Г. С. Сухобской [12], Т. В. Шадриной [14], и др., которые рассмотрели различные аспекты самоактуализации личности в сфере образования взрослых.

Практическая значимость исследования заключается в том, что представленные в статье психологопедагогические условия, способствующие самоактуализации человека третьего возраста в образовательном пространстве Высшей народной школы, могут быть воссозданы в образовательном учреждении, в общественной организации, в сфере социальной защиты населения для организации работы с людьми третьего возраста.

\section{Теоретико-методологические основы исследования Высшей народной школы как пространства самоактуализации человека третьего возраста}

Понятие «самоактуализация личности» введено в научный дискурс в середине XX века в США и с тех пор является системообразующим для гуманистической психологии. Это понятие по своей природе действительно глубоко гуманистично, поскольку исполнено веры в возможности человека управлять своим развитием, реализовывать свой потенциал, усилием мысли и воли творить свое «Я». Потребность в самоактуализации является органичной для каждого человека. Возможность её реализации обусловлена уровнем социально-психологической и социальной зрелости личности. Не случайно один из основателей гуманистического подхода в психологии А. Маслоу расположил самоактуализацию на высшем уровне в его пирамиде потребностей. Путь на вершину труден. В этом восхождении человек остается один на один со своими слабостями, пороками, мечтами, задатками, силой воли. Многие так и не достигают вершины, довольствуясь минимальным комфортом и удовлетворением утилитарных потребностей. И все же есть те, кто выходит на уровень самоактуализации. Человек по природе своей социален, и, конечно, общество в определенной мере влияет на его личностное становление, предлагая социальные ориентиры и образцы, но определяющими всетаки являются внутренняя мотивация и готовность действовать. Мотив самоактуализации отражает желание человека быть собой, жить в согласии со своей природой. Самоактуализирующийся человек сам стремится строить свою жизнь, творить самого себя. Он активен и ищет возможности для своего личностного роста. Процесс достижения социально-психологической и социальной зрелости человека глубоко индивидуален, обусловлен личностными особенностями, социальной средой, но не возрастом. Для пожилых людей он также актуален и доступен. Укоренившийся в обществе стереотип пожилого человека коррелирует с самим понятием «пожилой», т.е. уже поживший и, в общем, доживающий свой век. Альтернативой этой позиции являются стратегия активного долголетия и соответствующее ей понятие «третий возраст». Английский демограф Питер Ласлетт предложил рассматривать жизненный цикл современного человека состоящим из четырех стадий, добавив «третий возраст» в традиционную классификацию «детство - взрослость - старость», в этой схеме старость - «четвертый возраст» [Цит. по: 7, с. 68]. «Третий возраст» как стадия в жизненном цикле человека - это новое для общества демографическое явление, обусловленное увеличением продолжительности жизни. Представители третьего возраста отнесены к возрастной группе «молодых стариков» - звучит парадоксально: это люди, достигшие возраста старости в его традиционном понимании (примерно 60-75 лет), но сохранившие активную жизненную позицию, профессиональную мобильность, физическую выносливость и оптимистичный взгляд на мир.

Как отмечают демографы, в большинстве развитых стран уже в 1940-1960-х годах сформировался возрастной слой «молодых стариков» [6]. В своих исследованиях демограф В. Г. Доброхлеб констатирует: «В России по экспертным оценкам начал складываться слой представителей третьего возраста». Далее автор приходит к следующему выводу: «...переход к экономике знаний требует нравственных высококвалифицированных здоровых работников, что в условиях стареющего общества возможно при создании институтов, способствующих активному долголетию» [7, с. 72].

Отметим, что человек имеет не только биологическую, но и социальную продолжительность жизни. Следовательно, старение происходит не только под влиянием биологических факторов, но и под влиянием социальных факторов, которые, по мнению классика отечественной демографии Б. Ц. Урланис, играют 
решающую роль в интенсивности старения [13, с. 358]. Третий возраст, как демографический феномен, социально обусловлен, и он подарил пожилым людям дополнительные годы активной жизни. Появился шанс осуществить мечты, компенсировать недостающие знания, выйти на уровень самоактуализации. Общество должно создать для этого благоприятные условия. Осознание проблемы на уровне властных структур существует. Примером вдумчивого, экспертного подхода является «Стратегия действий в интересах граждан старшего поколения в Российской Федерации до 2025 года» (Распоряжение Правительства Российской Федерации от 5 февраля 2016 г. № 164-р). Авторы документа подчеркивают, что «результатом реализации Стратегии является создание условий для активного долголетия граждан старшего поколения, которые позволят повысить уровень и качество жизни таких граждан» [11]. В текущем году должен начаться второй этап реализации Стратегии (запланирован с 2020 до 2025 года) [Там же], однако реальных шагов по созданию условий для активного долголетия наших граждан так и не было сделано.

Между тем проблема позитивного старения в меру сил решается общественными организациями, учреждениями культуры, образования. В качестве примера эффективной деятельности с людьми третьего возраста мы предлагаем рассмотреть опыт Высшей народной школы (ВНШ), действующей уже более 11 лет на базе Педагогического института Иркутского государственного университета.

На рубеже XX-XXI вв. в ряде городов России (Санкт-Петербург, Владивосток, Барнаул, Иркутск и др.) начали открываться Высшие народные школы (ВНШ) для людей пенсионного возраста. Это общественнообразовательное движение было инициировано и поддержано создателем первой Высшей народной школы в современной России Ниной Петровной Литвиновой, доктором экономических наук, ярким общественным деятелем [10]. По сути, это были социальные проекты, ориентированные на доступное неформальное, информальное образование человека третьего возраста, в основе которого лежали бесплатное обучение и добровольческий труд преподавателей.

Неформальное образование - это пространство добровольческого взаимодействия людей в целях удовлетворения их потребности в новых, актуальных для них знаниях, потребности в общении и личностном развитии. В неформальном образовании нет стандартов, сертификатов, влияющих на карьерный рост, «здесь царят свобода выбора и высокая учебная мотивация. Как правило, неформальное образование благодаря своей гибкости носит опережающий характер и позволяет человеку идти в ногу со временем...» [5, с. 5]. Если неформальное образование предполагает создание учебной ситуации, в которой взаимодействуют педагог и группа обучающихся, в информальном - процесс познания происходит на индивидуальном уровне (чтение книг, поиск информации в социальных сетях, общение с интересным человеком и т.д.). «Информальное образование олицетворяет готовность человека к самообучению, к индивидуальному познанию, лишенному строгой регламентации, пространственных и временных границ» [Там же].

Народные школы в силу своей надынституциональности свободны в выборе направлений деятельности, технологий преподавания, структуры процесса образования. ВНШ ориентированы не на образовательный стандарт или социальный заказ, а на познавательные потребности и интересы обучающих и обучающихся. Отметим, что появление ВНШ в постсоветский период стало не столько зарождением, сколько возвращением (конечно, в обновленном виде) в российское образовательное пространство тех самых народных школ, которые были популярны в нашем Отечестве во второй половине XIX - начале XX века и вошли в историю как «воскресные школы», «народные школы», «народные университеты» [4, с. 13-24].

Современные Высшие народные школы открываются общественными организациями, учреждениями социальной защиты, культуры, образования. В настоящее время уже можно говорить об успешном опыте создания народных школ для взрослых на базе вузов [Там же, с. 72-90]. Этот опыт пока не получил широкого распространения в России, но содержание деятельности народных школ и её эффективность в создании условий для активного долголетия людей третьего возраста заслуживают внимания. Рассмотрим в качестве примера деятельность Высшей народной школы Иркутска [4]. По инициативе кафедры социальной педагогики и психологии Педагогического института Иркутского государственного университета (ИГУ) в феврале 2009 г. была создана первая в Восточной Сибири Высшая народная школа. Это общественная инициатива, которой педагоги и студенты посвящают свободное от занятий время. В ВНШ учебный год совпадает с учебным годом и семестрами вуза, а учебная неделя составляет 6 дней. Формы обучения: научно-популярные лекции, практические занятия по иностранным языкам, компьютерной грамотности, лечебной физкультуре, коммуникативные тренинги, работа творческих клубов и кружков по интересам, позволяющих участникам реализовать свой творческий потенциал и социализироваться.

Особенность и актуальность складывающейся современной модели народной школы в том, что её целевой группой являются активные пенсионеры, а образовательное пространство школы функционирует как социальная сеть. Социальными партнерами школы являются: профессорско-преподавательский состав вузов города, аспиранты, представители искусства, бизнеса, власти и т.д. Высшая народная школа является площадкой для реализации смелых педагогических идей преподавателями вуза, для которых опыт работы с людьми третьего возраста является новым и представляет профессиональный интерес. Но главное значение деятельности народной школы заключается в качестве выстроенного андрагогического взаимодействия и обусловленных им педагогических, социально-психологических и социальных эффектах, которые в целом создают условия для самоактуализации человека третьего возраста. 
Самоактуализация как полноценное использование человеком своих способностей, потенциала, задатков предполагает достижение социально-психологической зрелости. Выдающийся отечественный психолог, андрагог Г. С. Сухобская определила показатели социально-психологической зрелости человека:

- самостоятельное прогнозирование своего поведения в любых жизненных ситуациях на основе умения добывать нужную информацию и анализировать ее применительно к целям, связанным с решением конкретных и нестандартных ситуаций во всех сферах жизнедеятельности;

- мобилизация себя на выполнение собственного решения о действии вопреки различным обстоятельствам и внутреннему социально не мотивированному желанию его прекратить («устал», «не хочу», «трудно» и т.д.);

- самостоятельное отслеживание хода выполнения собственных действий и их результатов;

- проявление оценочной рефлексии на основе сформированного самосознания и объективной оценки своих мыслей, действий, поступков;

- способность «извлекать уроки» из собственного поведения в различных ситуациях;

- эмоционально-адекватная реакция на различные ситуации собственного поведения [12, с. 19].

Автор также подчеркивает, что, наряду с социально-психологической, формируется социальная зрелость, которую следует связывать с позитивной направленностью, т.е. внутренней установкой личности на гуманистические ценности.

В образовательном пространстве Высшей народной школы в качестве педагогических, социальнопсихологических и социальных эффектов деятельности представлены все показатели социально-психологической зрелости личности, определенные Г. С. Сухобской. Остановимся на этом подробнее. Взаимодействие преподавателей, студентов вуза и слушателей ВНШ является андрагогическим [14, с. 24], т.е. это процесс взаимного влияния, основанный на системе межсубъектных связей, предполагающий формирование ситуации межсубъектного взаимодействия в ходе обучения [8, с. 79].

Стержнем образовательного процесса школы являются научно-популярные лекции, которые по своему содержанию и форме изложения оптимально соотнесены с задачами третьего возраста. Большое внимание уделяется психологии общения, жизнестойкости, развитию памяти. Активно применяются упражнения, направленные на актуализацию ресурсов мозга (нейробика). Кроме этого, по запросу слушателей приглашаются для чтения лекций специалисты в сфере экономики, права, управления. Большой популярностью пользуется гуманитарная проблематика (история, литература, журналистика, искусствоведение и др.). Возможность получить актуальные знания, позволяющие разобраться в своих чувствах, найти свои смыслы и сформировать мотивацию достижения целей, позволяет слушателям мобилизовать себя на выполнение действий по саморазвитию, самореализации и при помощи методик и рекомендаций преподавателей самостоятельно отслеживать ход выполнения этих действий и их результаты. Таковы педагогические эффекты деятельности народной школы.

Большую часть учебного времени слушатели ВНШ проводят в групповых занятиях. Увлеченно изучают иностранные языки. Разговорный английский пользуется большим спросом и преподается в форме ролевой игры, пения, инсценирования. Взаимодействие со студентами-волонтерами, как правило, осуществляется в форме тренинга (коммуникативного, командообразования, развития творческих способностей и др.). Будущие психологи и социальные педагоги в рамках этих занятий создают условия для проявления оценочной рефлексии на основе знаний и богатого жизненного опыта, мотивируют слушателей к объективной оценке своих мыслей, действий, поступков. Часть групповых занятий посвящена арт-терапии, их проводит опытный психотерапевт. Здесь получает развитие способность «извлекать уроки» из собственного поведения в различных ситуациях, появляется возможность стабилизации эмоционально-волевой сферы личности. Все эти новообразования относятся к социально-психологическим эффектам деятельности школы.

Большое значение для самоактуализации человека третьего возраста имеет возможность компенсировать недостаточность знаний, навыков в тех сферах деятельности, которые не связаны с его профессией, привлекали всегда, но из-за отсутствия времени не могли получить развития. Теперь, с выходом на пенсию, такая возможность появилась. Народная школа создает условия для творческой самореализации слушателей. Здесь работают студии, кружки, клубы, способные удовлетворить самые разнообразные познавательные запросы людей третьего возраста и создать для них ситуацию успеха. Важно, что творческие достижения слушателей становятся достоянием широкой общественности через издание литературным клубом Высшей народной школы альманахов «Родные берега» (художественно-публицистический) и «Народное обозрение» (научнопублицистический), концертные выступления студии «Живое слово», выставки живописи, художественной фотографии, прикладного искусства, которые проходят в ведущих выставочных залах города.

Образовательное пространство Высшей народной школы с самого её основания вышло за рамки вуза в широкий социум. Слушатели создали волонтерский отряд «Неугомонные», деятельность которого по организации экологических десантов, курированию детских домов, домов престарелых высоко ценится в регионе. Служение людям, нуждающимся в помощи, родному краю и общественное признание, самозабвенное творчество и успех, разнообразие освоенных социальных ролей (слушатель, преподаватель, творец, волонтер и др.) и появление круга друзей, единомышленников являются важнейшими социальными эффектами функционирования образовательного пространства народной школы и подтверждением социальной зрелости её слушателей.

Все эффекты андрагогического взаимодействия в пространстве Высшей народной школы (педагогические, социально-психологические, социальные) были подтверждены в ходе включенного наблюдения, глубинных интервью, с применением методик, измеряющих уровень социального самочувствия и качества жизни людей третьего возраста. В исследовании был использован адаптированный А. В. Лазукиным тест 
А. Маслоу «САМОАЛ», который раскрывает 11 важнейших характеристик самоактуализирующейся личности (ориентация во времени, ценности, взгляд на природу человека, потребность в познании, креативность (стремление к творчеству), гибкость в общении, автономность, спонтанность, самопонимание, аутосимпатия, контактность) [3, с. 65-75]. По всем показателям была выявлена положительная динамика. Высшая народная школа Иркутска действует уже более 11 лет без финансирования, без определенного правого статуса, но при постоянной поддержке (в виде учебных помещений, лекций) со стороны общественности города и самих слушателей.

\section{Заключение}

Таким образом, мы пришли к выводам, которые соответствуют общему смыслу работы.

1. На основании проведенного теоретико-методологического исследования можно констатировать, что Высшая народная школа является пространством самоактуализации человека третьего возраста. Реализация и развитие данной формы обучения взрослых является одним из перспективных направлений психолого-педагогических исследований.

2. Наиболее актуальными проблемами при самоактуализации человека третьего возраста оказались проблемы, связанные с наличием устойчивых стереотипов в обществе о пожилых людях как объектах обслуживания, доживающих свой век. Полагаем, что педагогической общественности необходимо обратить внимание на эту возрастную категорию, приложить консолидированные усилия для создания образовательных площадок, способствующих самоактуализации людей третьего возраста.

3. Выделены разные направления деятельности Высшей народной школы, которые способствуют развитию социально-психологической и социальной зрелости слушателей. Зафиксированы педагогические, социально-психологические, социальные эффекты, возникающие в условиях андрагогического взаимодействия преподавателей и слушателей народной школы.

4. Обоснованы психолого-педагогические условия, способствующие самоактуализации человека третьего возраста в образовательном пространстве Высшей народной школы:

- образовательный процесс Высшей народной школы носит гибкий, вариативный характер, содержание и структура деятельности соотнесены с задачами третьего возраста;

- процесс андрагогического взаимодействия носит исключительно субъект-субъектный характер, в качестве субъектов выступают: преподаватели, студенты вуза, слушатели ВНШ, представители общественности;

- образовательное пространство школы функционирует как социальная сеть. Социальными партнерами являются: профессорско-преподавательский состав вузов города, аспиранты, представители искусства, бизнеса, власти и т.д.;

- в процессе обучения слушатели получают возможность творческой самореализации, для них создается ситуация успеха, общественного признания;

- важным направлением деятельности школы является добровольное служение обществу, помощь тем, кто в ней нуждается (дети-сироты, инвалиды, получатели социальных услуг в домах престарелых и др.).

Соблюдение данных психолого-педагогических условий будет способствовать повышению уровня социальнопсихологической и социальной зрелости людей третьего возраста, развитию у них устойчивой мотивации к оптимальной реализации внутреннего потенциала личности, что в итоге создаст предпосылки для самоактуализации.

\section{Список источников}

1. Вахромов Е. Е. Психологические концепции развития человека: теория самоактуализации: учеб. пособие / Моск. пед. ун-т. М.: Междунар. пед. акад., 2001. 158 с.

2. Вершловский С. Г. Андрагогика: учеб.-метод. пособие. СПб.: СПб АППО, 2014. 148 с.

3. Вопросник самоактуализации личности // Журнал практического психолога. 1998. № 1. С. 65-75.

4. Гордина О. В. Народная школа: ретроспектива, экстраполяция в современное социальное пространство Сибири: монография. Иркутск: ВСГАО, 2014. 152 с.

5. Гордина О. В., Гордин А. И. Информальное и неформальное образование взрослых: вопросы теории и практики: монография. Иркутск: ВСГАО, 2010. 184 с.

6. Денисенко М. Тихая революция // Отечественные записки. 2005. № 3. С. 16-31.

7. Доброхлеб В. Г. Старение населения как фактор модели демографического перехода на примере современной России // Социологический альманах. 2012. № 3. С. 67-73.

8. Казакова М. А. Понятие и сущность андрагогического взаимодействия в отечественных и зарубежных исследованиях // Современные исследования социальных проблем. 2017. Т. 8. № 1. Ч. 1. С. 61-79.

9. Леонтьев Д. А. Развитие идеи самоактуализации в работах А. Маслоу // Вопросы психологии. 1988. № 1. С. $150-185$.

10. Литвинова Н. П. Тенденции и перспективы развития Высших народных школ // Человек и образование. 2010. № 4. С. 15-19.

11. Стратегия действий в интересах граждан старшего поколения в Российской Федерации до 2025 года [Электронный ресурс]. URL: https://mintrud.gov.ru/ministry/programms/37/2 (дата обращения: 08.07.2020). 
12. Сухобская Г. С. Понятие «зрелость социально-психологического развития человека» в контексте андрагогики // Новые знания. 2002. № 4. С. 18-19.

13. Урланис Б. Ц. Послесловие // Процесс старения населения. Демографические исследования. М.: Статистика, 1968. С. 357-360.

14. Шадрина Т. В. Андрагогические подходы к обучению будущих специалистов сферы профессионального образования // Современное образование: традиции и инновации. 2015. № 1. С. 23-29.

\section{Информация об авторах | Author information}

RU Гордина Ольга Васильевна ${ }^{1}$, к. пед. н., доц.

Гордин Александр Иннокентьевич ${ }^{2}$, к. пед. н., доц.

${ }^{1,2}$ Иркутский государственный университет

EN Gordina Olga Vasilevna ${ }^{1}, \mathrm{PhD}$

Gordin Aleksandr Innokentevich ${ }^{2}, \mathrm{PhD}$

${ }^{1,2}$ Irkutsk State University

1'g.o.v.2018@mail.ru,2a-gordin58@mail.ru

Информация о статье | About this article

Дата поступления рукописи (received): 09.07.2020; опубликовано (published): 30.10.2020.

Ключевые слова (keywords): самоактуализация; третий возраст; Высшая народная школа; андрагогическое взаимодействие; психолого-педагогические условия; self-actualization; third age; Higher Public School; andragogic interaction; psychological and pedagogical conditions. 